\title{
O CONTROLE JURISDICIONAL DAS POLÍTICAS PÚBLICAS E O PAPEL DO ESTADO: UMA ANÁLISE HABERMASIANA
}

\section{THE JUDICIAL CONTROL OF PUBLIC POLICIES AND THE ROLE OF STATE: AN ANALYSIS HARBERMASIAN}

Gabriela Soares Balestero ${ }^{1}$

\begin{abstract}
RESUMO: A finalidade do presente estudo é analisar o controle jurisdicional das políticas públicas diante das atuais necessidades da sociedade, com o objetivo de assegurar a aplicação dos direitos fundamentais, em especial os sociais prestacionais, alcançando efetivamente o Estado Democrático de Direito. Os administradores públicos e os magistrados devem estar atentos aos problemas da comunidade.
\end{abstract}

Palavras Chave: Controle jurisdicional; Políticas Públicas; Princípio da reserva do possível; Mínimo existencial; Participação popular; Democracia.

\begin{abstract}
The purpose of this study is to analyze the judicial control of public policies in the face of current needs of society, in order to ensure the application of fundamental rights, especially the social prestaciones, effectively reaching the democratic state of law. Public administrators and magistrates must be attentive to the problems of the community.
\end{abstract}

Keywords: The Judicial Control; Public Policies; Principle of reservation as possible; Low Existencial; Popular participation; Democracy.

\section{INTRODUÇÃO}

Analisaremos o controle jurisdicional das políticas públicas relacionando-o com o princípio da reserva do possível e o mínimo existencial, especialmente para assegurar a eficácia e a efetividade dos direitos fundamentais, analisando com maior profundidade o tema referente às políticas públicas e o seu alcance no cenário do direito administrativo.

A expressão "políticas públicas" constitui um conjunto de ações desenvolvidas pelo Poder Público com vistas à satisfação do bem comum, da coletividade. Nesse sentido, a política pública é um bem de toda a comunidade.

As políticas públicas possuem um sentido de complementaridade com os direitos fundamentais, em especial, os prestacionais, previstos na Constituição Federal. Verifica-se, então, a necessidade da implantar políticas públicas sérias na tentativa de alcançar a legitimação do Estado Democrático de Direito, e é preciso mudar a postura, na maioria das vezes, arbitrária do administrador público passando a desenvolver o diálogo e a participação social, comunitária. ${ }^{1}$ Gabriela Soares Balestero. Mestranda em Direito Constitucional pela Faculdade de Direito do Sul de Minas, especialista em Direito Constitucional e em Direito Processual Civil pela Faculdade de Direito do Sul de Minas. Advogada militante graduada pela Universidade Presbiteriana Mackenzie em 2.006. Endereço eletrônico para contato: gabybalestero@yahoo.com.br. 
Por fim, será discutida a postura do Poder Judiciário no controle das políticas públicas para alcançar o equilíbrio nas decisões judiciais, devendo elas serem justas, respeitando os direitos fundamentais previstos constitucionalmente e, ao mesmo tempo, limitarem o uso indiscriminado da coisa pública pela administração.

\section{AS POLÍTICAS PÚBLICAS E A EFETIVIDADE DOS DIREITOS FUNDAMENTAIS}

Até que ponto a Administração Pública pode obstacularizar a prestação dos direitos fundamentais, apresentando com justificativa o princípio da reserva do possível. ${ }^{2}$

O princípio da reserva do possível não deve ser utilizado de forma de inibir a eficácia e a aplicação do "mínimo existencial" (embora os direitos sociais não devam ser reduzidos ao mínimo), especialmente no que tange aos direitos fundamentais sociais prestacionais, como a saúde, a vida, pois a todas as normas de direitos fundamentais há de se outorgar a máxima eficácia e efetividade possível, sempre à luz do caso concreto.

Nesse sentido, baseado no entendimento doutrinário e jurisprudencial alemão, atendendo ao debate de Weimar, limitar o mínimo existencial apenas ao alcance fisiológico do indivíduo, desprezando o mínimo social, ocasionaria a redução da aplicabilidade não só dos direitos fundamentais sociais prestacionais, mas do próprio mínimo, de modo a colocar em risco a sobrevivência do ser humano.

É o que ocorre no caso, por exemplo, do direito à saúde, que, além de ser um direito fundamental social prestacional do Poder Público, é também um direito de defesa, de proteção contra atos do Estado ou de particulares.

Dessa forma, ao fazer referência à Constituição brasileira, a doutrina atual se projeta no sentido de dar plena aplicabilidade às normas constitucionais que regem os direitos fundamentais sociais prestacionais, em especial, os direitos sociais. Ela não esvazia o mínimo

\footnotetext{
${ }^{2}$ Com efeito, por ocasião do julgamento do Recurso Extraordinário n. 267.612-RS (decisão publicada no DJU de 23.08.2000), o eminente Relator, Ministro Celso de Mello, em hipótese versando justamente sobre o fornecimento de medicamentos para o tratamento da Aids, consignou que "o direito público subjetivo à saúde representa prerrogativa jurídica indisponível assegurada à generalidade das pessoas pela própria Constituição da República (art. 196). Traduz bem jurídico constitucionalmente tutelado, por cuja integridade deve velar, de maneira responsável, o Poder Público, a quem incumbe formular - e implementar - políticas sociais e econômicas que visem a garantir, aos cidadãos, o acesso universal e igualitário à assistência médico-hospitalar. O caráter programático da regra inscrita no art. 196 da Carta Política - que tem por destinatários todos os entes políticos que compõem, no plano institucional, a organização federativa do Estado brasileiro - não pode converter-se em promessa constitucional inconseqüente, sob pena de o poder público, fraudando justas expectativas nele depositadas pela coletividade, substituir, de maneira ilegítima, o cumprimento de seu impostergável dever, por um gesto irresponsável de infidelidade governamental ao que determina a própria Lei Fundamental do Estado." (extraído das transcrições efetuadas no Boletim Informativo do STF).
} 
existencial e mantém a sua condição de direito e garantia, independentemente de sua previsão constitucional expressa, não dispensando a análise de cada caso concreto.

Além disso, é pertinente ressaltar que as decisões do Poder Público para a construção de suas metas de ação não são invioláveis, impenetráveis pelo Poder Judiciário, construindo-se a noção de que no âmbito do Estado Democrático de Direito é possível controlar as políticas públicas. $^{3}$

A Administração Pública deve voltar-se para o dever de realizar e efetivar a Constituição na preservação dos direitos fundamentais, construindo um conjunto de ações governamentais com o escopo de alcançarmos efetivamente a implantação de um Estado Democrático de Direito.

Portanto, é necessário relacionar o exercício das políticas públicas com a Constituição Federal e vinculá-las às ações da Administração Pública.

Problematizar tal tema significa refletir sobre o próprio conceito de democracia de maneira a garantir, da melhor forma possível, um tratamento igualitário para toda a comunidade, e efetivar as políticas públicas .

Além disso, é imprescindível reconhecer a importância da participação popular, a atuação dos chamados "atores sociais", de maneira a qualificar as políticas públicas, dando - lhes maior eficiência, pois alcançarão as necessidades da comunidade.

É necessário criar instituições que canalizem o direito à participação direta na gestão política. Esse entendimento é embasado por teorias conhecidas como o contratualismo de Jean Jacques Rousseau, na qual a sociedade política deve ser criada para, ao mesmo tempo, conservar a soberania e preservar a liberdade humana, tendo em vista ser esta inalienável, numa fusão entre ato de obediência e ato de liberdade: "A concepção de participação em Rousseau consubstancia o manancial teórico que inspirou diretamente todas as abordagens que, de uma forma ou de outra, destacam a importância da introdução de elementos de democracia direta, quando não a sua completa adoção.” (PEREIRA, 2008, p. 152)

Para Rousseau, a participação de todos na sociedade e a sujeição de todos à vontade comum obstam o exercício de interesses pessoais. Nesse sentido, esse princípio participativo

\footnotetext{
${ }^{3}$ Qualquer política pública, desta forma, deve estar vocacionada para fazer acontecer (Ereignis) os objetivos fundamentais da República Federativa do Brasil indicados no artigo $3^{\circ}$ da Constituição Federal, como já explicitado anteriormente. Tais indicações já se constituem por si em indicações de políticas públicas, sequer havendo liberdade de ação política para os Poderes Públicos desprezarem tais fundamentos. A Constituição erigiu como importantes bens para a comunidade, por exemplo, a solidariedade e a proibição de práticas discriminatórias. Cabe ao Estado desenvolver programas de políticas públicas que internalizem tais bens jurídicos no imaginário da sociedade, sendo importante que os cidadãos igualmente assumam a responsabilidade fenomenológica de fazer acontecer tais indicações constitucionais, exigindo ações governamentais em tal direção. (OHLWEILER, 2008, p. 332).
} 
ocorre tanto no ato de associação quanto no exercício do poder.

\begin{abstract}
Recentemente, a versão mais exponenciada da associação entre proteção e participação encontra-se no conceito de partizipative Siherheitsstaat ("Estado de segurança participativo" criado por MATHIAS KOTTER). Ao abordar a temática da segurança pública, o autor faz emergir a dimensão participativa como o vetor essencial para o combate tanto das ameaças tradicionais, quanto das ameaças modernas, catalisadas através da figura emblemática do terrorismo. Segundo suas perspectivas, a situação ideal de segurança pública depende imediatamente da existência de uma rede de cooperação entre Estado e cidadãos que sustente a transposição da regulação exclusivamente estatal da questão da segurança para a auto-regulação social influenciada pelo Estado. (PEREIRA, 2008, p. 154-155).
\end{abstract}

A participação popular, portanto, gera uma produção dialética e eficaz, pois havendo um panorama global de interesses, aumentam os debates, que podem originar decisões mais eficientes e maior proteção, já que a participação social cria a transparência e polícias mais eficientes, legitimando-se as "esferas públicas".

Em suma, a sociedade do risco imprime constitucionalmente a necessidade de participação dos cidadãos, o aumento das garantias protetivas contra o Estado e os detentores do poder, bem como a transparência dos procedimentos e das funções públicas.

Nesse passo, portanto, uma questão deve ser debatida: a necessidade de repensar as estruturas administrativas, ainda maculadas pelo estereótipo do racionalismo, de maneira a adaptá-las aos princípios constitucionais.

Infelizmente, em nosso modelo de organização administrativa ocorre ainda a centralização dos processos de decisão e de construção de programas de ação, o que leva a desconsiderar as realidades locais. Precisa acontecer o oposto disso, as ações administrativas devem ser pautadas em um planejamento moderado, proporcional, de maneira a se adequar às comunidades nas quais se aplicam.

\footnotetext{
A implementação do princípio da participação popular no governo, consoante o Estado Democrático de Direito, é um remédio a ser aplicado para corrigir essa ausência de diálogo de uma sociedade oligárquica e patrimonialista. Daí sobrelevar-se a importância da educação política como condição inarredável para uma cidadania ativa numa sociedade republicana e democrática. (SOARES, 2001, p. 328).
}

Com o princípio da representação verifica-se o distanciamento exacerbado entre a esfera política e a esfera pessoal, e, portanto, é necessário o exercício do princípio da integração, aproximando o cidadão da política. 


\begin{abstract}
No entanto, para materializar políticas públicas é imperioso que os governos e a própria sociedade assumam-se como co-responsáveis por este processo e tenham a capacidade de construir espaços públicos de aprendizagem social, quer dizer, um planejamento temporalizado, mas preparado para o acontecer ou os fracassos possíveis da democracia. (OHLWEILER, 2008, p. 336).
\end{abstract}

Consoante o entendimento de Mário Lúcio Quintão Soares (2001, p. 307), “esta nova cidadania, erigida pelo novo paradigma, consiste na capacidade de participar no exercício do poder político e da gestão dos negócios da comunidade. As formas desse exercício definem os meios diretos ou não de participação dos cidadãos".

Portanto, é evidente a contribuição positiva dos movimentos sociais para o fortalecimento das práticas democráticas, pois eles são atores que canalizam as principais preocupações e necessidades da população: $1^{\circ}$ ) facilitam a criação de elos para o entendimento mútuo; $2^{\circ}$ ) promovem o reconhecimento, a reconstrução e a proteção de identidades coletivas marginalizadas; $3^{\circ}$ ) facilitam a melhor representação dos interesses; $4^{\circ}$ ) promovem a abertura dos canais participativos; $5^{\circ}$ ) viabilizam a externalização dos dissensos, ou seja, a prática de tais movimentos tem como efeito direto tornar públicas as diversidades de interesses e as suas complexidades; $6^{\circ}$ ) exponenciam os índices de eficácia das funções de fiscalização e controle do poder.

A efetividade da implementação de políticas públicas ocorre apenas com a integração entre o cidadão e o Poder Público de maneira a fazer acontecer os planos construídos, exigindo certas estratégias como debates e audiências públicas para aspirar às necessidades da comunidade, quebrando o "tabu" de uma organização administrativa clássica hierárquica, do administrador autoritário, ditatorial.

Dessa forma, na democracia, a participação do cidadão no poder configura-se pela efetiva atuação em movimentos sociais em suas comunidades, concretizando a cidadania sob o prisma legal.

\title{
O CONTROLE JURISDICIONAL DAS POLÍTICAS PÚBLICAS
}

O controle jurisdicional das políticas públicas remete-nos a mencionar o controle jurisdicional sobre a Administração Pública.

$\mathrm{Na}$ atualidade, alguns apresentam como solução o controle judicial sobre o Poder Legislativo e os atos do Poder Executivo, na forma de prestação de contas, para a efetivação dos direitos fundamentais. 
Logo, é possível evidenciar que o controle jurisdicional das políticas públicas fundado no constitucionalismo poderá dimensionar dois âmbitos importantes do conjunto de ações governamentais: formal e material. Por certo sem cair em dicotomizações, cabe ao Poder Judiciário garantir que as políticas públicas adotem uma processualidade capaz de salvaguardar a legitimidade democrática. O que antes foi indicado como necessário para o processo de construção de políticas públicas, com certeza, pode ser levado ao controle jurisdicional como forma até mesmo de realizar a transparência administrativa. (OHLWEILER, 2008, p. 339-340).

O Poder Judiciário também pode criar comissões como, por exemplo, a Procuradoria Geral do Estado do Rio Grande do Sul - "PGE Saúde" (MELO, 2008, p. 108) para controlar o cumprimento, pelo Poder Público, das decisões judiciais favoráveis à prestação de direitos fundamentais sociais prestacionais, especialmente no que toca à saúde e à vida, não havendo, portanto, uma liberdade impenetrável dos agentes públicos. E o exercício do controle por parte do Poder Judiciário não representa uma violação ao princípio da separação de poderes.

Destaca-se o entendimento do Ministro Eros Grau no sentido de que a reserva do possível "não pode ser reduzida a limite posto pelo orçamento, até porque, se fosse assim, um direito social sob 'reserva de cofres cheios' equivaleria, na prática'[...] como diz José Joaquim Gomes Canotilho (2001) - a nenhuma vinculação jurídica.

Nesse passo, em complemento à citação supramencionada, é forçoso compreender que os direitos fundamentais sociais são plenamente eficazes independentemente da tentativa de restrição de sua aplicabilidade pelo Poder Público.

Ressalta-se que a Constituição Federal possui hierarquia máxima, não devendo ser desvalorizada, estando o administrador vinculado à sua obediência, mediante uma melhora na organização dos orçamentos e pela aplicação dos princípios da moralidade e da probidade administrativa no que tange à alocação e destinação dos recursos públicos, com o auxílio do controle do Poder Judiciário.

Portanto, não é necessária uma reforma constitucional para disciplinar a forma de execução dos direitos fundamentais sociais prestacionais, tanto em sua amplitude quanto em seu mínimo, mas apenas uma melhoria das leis infraconstitucionais buscando superar omissões legislativas ou lacunas orçamentárias ${ }^{4}$, e o cumprimento efetivo, pela Administração, da Constituição Federal, otimizando a aplicação dos direitos fundamentais sociais prestacionais, em

\footnotetext{
${ }^{4}$ Nesse sentido, é interessante o entendimento de Torres (2008, p. 83): “Se não prevalece o princípio da reserva do possível sobre o direito fundamental ao mínimo existencial, nem por isso se pode fazer a ilação de que não deve ser observado o princípio da reserva do orçamento. A superação da omissão do legislador ou da lacuna orçamentária deve ser realizada por instrumentos orçamentários, e jamais à margem das regras constitucionais que regulam a lei de meios. Se, por absurdo, não houver dotação orçamentária, a abertura dos créditos adicionais cabe aos poderes políticos (Administração e Legislativo), e não ao Judiciário, que apenas reconhece a intangibilidade do mínimo existencial e determina aos demais poderes a prática dos atos orçamentários cabíveis”.
} 
especial o direito à saúde. E, nas situações já consolidadas, aplicando o legislador o princípio da proibição do retrocesso social, devendo, sim, o Poder Judiciário atuar como controlador dos atos do administrador em prol da preservação dos direitos fundamentais.

Ademais, cabe ressaltar o entendimento de Luciano Benetti Timm (2008, p. 67) e de Ana Paula de Barcellos (2008, p. 146) de que os recursos orçamentários obtidos por meio da tributação, incluindo a abertura de créditos adicionais, devem ser empregados pelo Poder Público de modo mais eficiente para que possa atingir o maior número de demandas da população, cumprindo as metas fixadas. Isto é, devem ser implementadas políticas públicas e sociais, evitar o desperdício de recursos públicos, de maneira à efetivamente aplicá-los na melhora da qualidade da prestação dos direitos fundamentais sociais. Para isso, devem existir atores públicos mais capacitados, conhecedores das diversas disciplinas tanto humanas quanto exatas, como direito, economia e sociologia, com o escopo de obter uma administração mais eficiente no que tange à aplicação dos recursos públicos.

\section{HABERMAS}

Jürgen Habermas trouxe uma contribuição ao campo do Direito, mais precisamente da filosofia política, pois através da teoria do discurso ou da ação argumentativa, afirma que o Direito é um meio de integração social, é um mediador da tensão entre a facticidade, ou seja, o mundo real, e a validade.

Para Habermas há três tipos de racionalidade: a) racionalidade teleológica que é ligada aos fins, à obtenção da verdade, ou pelo menos, uma verdade construída, baseada em argumentos; b) a racionalidade normativa, na qual o Direito é utilizado como um instrumento, como uma justificativa, pois, para todo comportamento, haveria uma explicação racional; c) racionalidade comunicativa na qual se busca alcançar pretensões de validade.

Ademais, para Habermas, haveria duas ações estratégicas: a integração sistêmica correspondente à economia, dinheiro e poder e a integração social que são as ações comunicativas, orientadas pelo consenso social, composta por outros elementos como os valores, a moral, a ética.

Nesse sentido, o Direito funcionaria como um mediador, um instrumento ${ }^{5}$, entre a facticidade e as pretensões de validade, como mecanismo de integração social.

\footnotetext{
5"Mas para atingir esse objetivo, Habermas indica transformações necessárias ao modo de produção e aplicação do direito. A fundamentação do direito e do Estado Democrático vai ser deslocada, da soberania do povo, para a soberania de um procedimento discursivo público sob condições ideais. O resultado é uma reconfiguração da separação dos poderes de acordo com os tipos de discursos predominantes em cada um deles. O poder administrativo (executivo), o legislativo e o judiciário ganham assim atribuições e competências cuja legitimidade pressupõe um outro poder, chamado por Habermas de 'poder comunicativo', que é o poder resultante de uma discussão pública racional onde todos os implicados passam a ser, ao mesmo tempo, destinatários e autores do próprio direito." (SIMIONI, 2007, p. 12.).
} 
No âmbito da jurisdição, Habermas divide a teoria do discurso em discursos de fundamentação ou de justificação das normas jurídicas e discursos de aplicação.

Nesse sentido, o Poder Judiciário não pode fazer discursos de justificação, ou seja, criar a norma jurídica, pois não há a participação popular, apenas podendo fazer discursos de aplicação.

O discurso de justificação não pode ser feito pelo Poder Judiciário enquanto ele não poder institucionalizar a participação popular em todas as decisões.

No caso dos orçamentos participativos, seria aberta a possibilidade dos cidadãos de, antes do encaminhamento do projeto de lei de diretrizes orçamentárias ao legislativo, a população opinasse sobre a destinação das verbas públicas, participando da elaboração da norma e da alocação de recursos públicos.

Segundo Rafael Lazzarotto Simioni (2007, p. 12-13) na teoria de Habermas, a normatividade do direito é fruto da legitimidade e os problemas de eficácia do direito, ou seja, da própria realização do direito, estariam atrelados à questão da legitimidade. Nesse sentido, sendo os cidadãos ao mesmo tempo destinatários e autores do direito passariam a assumir a responsabilidade individual pelo seu cumprimento.

Nesse passo, a legitimidade seria uma condição da força normativa do direito, transferindo o problema da realização dos direitos, que possui cerne positivista, para se tornar um problema de legitimação. Para isso, Habermas propõe um novo paradigma para o direito, denominado "procedimentalismo", na qual o direito gerado através do discurso democrático pode transformar a realidade, de maneira a diminuir as tensões sociais que existem.

Jürgen Habermas ${ }^{6}$ atribui um papel central à linguagem no processo de formação da opinião e da vontade dos cidadãos. Tal teoria se desenvolve no interior de um Estado Democrático de Direito que se pressupõem a existência de um espaço público não restrito ao âmbito estatal, de uma comunidade de homens livres e iguais capazes de criar as leis que os regem e onde os próprios envolvidos têm de entrar em acordo, prevalecendo a força do melhor argumento.

Habermas disserta sobre a tensão entre a facticidade e a validade constitutiva do Direito, sendo todo ato passível de ser confrontado com a Constituição. Nesse sentido, Habermas afirma:

Arrastada para cá e para lá, entre facticidade e validade, a teoria da política e do direito decompõe-se atualmente em facções que nada tem a dizer umas às outras. A tensão

\footnotetext{
$\overline{{ }^{6} \text { Essa legitimidade }}$ democrática, na modernidade, cabe esclarecer, remete-se ao chamado vínculo ou coesão interna entre Estado de Direito e Democracia, de que nos fala Habermas, fundamentalmente a partir do Direito e Democracia: entre fadicidade e validade." (OLIVEIRA, 2007, p. 5.).
} 
entre princípios normativistas, que correm o risco de perder o contato com a realidade social, e princípios objetivistas, que deixam fora de foco qualquer aspecto normativo, pode ser entendida como admoestação para não nos fixarmos numa única orientação disciplinar e, sim, nos mantermos abertos a diferentes posições metódicas (participante versus observador), a diferentes finalidades teóricas (explicação hermenêutica do sentido e análise conceitual versus descrição e explicação empírica), a diferentes perspectivas de papéis (o do juiz, do político, do legislador, do cliente e do cidadão) e a variados enfoques pragmáticos na pesquisa (hermenêuticos, críticos, analíticos, etc). (HABERMAS, 2003, p. 23).

Para Habermas, a teoria do Direito, sendo apoiada na Teoria do Discurso necessita sair da filosofia política e do direito e se expandir, ocasionando a reflexão sobre a possibilidade da construção de uma sociedade realmente pautada na justiça e na democracia.

Nesse sentido, Habermas (2003, p. 32) apresenta uma proposta baseada na Teoria do Discurso, que é a integração entre o Estado e a Sociedade Civil por intermédio de uma política deliberativa.

Em meio a essa situação surge a necessidade de que a teoria seja implantada na prática, utilizando como instrumento o Direito, como forma de justificar a Desobediência Civil no Estado Democrático de Direito ao criar um novo paradigma filosófico embasado na Teoria do Discurso de Jürgen Habermas, evidenciando a tensão entre a facticidade e a validade imanente ao Direito de um Estado Democrático em evolução, dando validade e aplicabilidade do Direito através do uso da linguagem.

\footnotetext{
A tensão entre facticidade e validade, que se introduz no próprio modo de coordenação da ação, coloca exigências elevadas para a manutenção de ordens sociais. $\mathrm{O}$ mundo da vida, as instituições que surgem naturalmente e o direito têm que amortizar as instabilidades de um tipo de socialização que se realiza através de tomadas de posição - em termos de $\operatorname{sim} /$ não - com relação a pretensões de validade criticáveis. (HABERMAS, 2003, p. 25-26).
}

Nessa vereda, a tensão entre a facticidade e a validade se traduz no Direito que possui o dever de estabilizar essas exigências da sociedade moderna de forma a propiciar a maior abertura do uso da comunicação e da linguagem, de maneira a gerar condições melhores de integração social.

Trata-se de um paradoxo, pois os direitos dos cidadãos abrem aos homens esferas de liberdade de arbítrio ocorrendo o mesmo em relação aos direitos políticos, que é a liberdade de comportamento conforme as regras. 
Consoante Habermas (2003, p. 115): "Para preencher a sua função de estabilização das expectativas nas sociedades modernas, o direito precisa conservar um nexo interno com a força socialmente integradora do agir comunicativo".

Nesse sentido, a partir da teoria do agir comunicativo o Direito adquire uma força socialmente integradora contribuindo positivamente para a evolução do Estado Democrático de Direito.

Nesse sentido, o Estado Democrático de Direito necessita de um sistema político que mantenha a conexão entre o poder administrativo e o poder comunicativo, pois o centro do Estado, encarregado da implementação das decisões, tende a se afastar da periferia, havendo o afastamento da comunicação e, em conseqüência a crise de legitimidade.

Consoante Maria Fernanda Salcedo Repolês (2003, p. 45), "somente pelo processo de constante construção de um Direito ao mesmo tempo coercitivo e legítimo que este pode cumprir o papel de integrador social".

Habermas questiona, frente à complexidade das sociedades modernas, se é possível manter os conceitos construídos pela filosofia da consciência de a) uma sociedade centrada no Estado; b) da relação entre partes e todo e, consequentemente, c) da sociedade composta pela soma de indivíduos.

Assim, com a teoria do agir comunicativo é dado ao Direito o papel de integrador social na sociedade em que vivemos; tendo como eixos a teoria do significado, a ligação entre o significado e a validade, a teoria dos atos da fala e o agir comunicativo, cujo objetivo é o alcance do entendimento mútuo, da prática da solidariedade e da autodeterminação dos cidadãos.

Habermas critica a perspectiva de Hobbes, tendo em vista que não há o reconhecimento pelo indivíduo de direitos subjetivos, mas sim a transferência de direitos ao Leviatã, ao Estado. Nesse sentido, para Hobbes haveria uma vontade geral pactuada em favor da paz e da preservação humana em torno da figura do Estado.

Como desenvolvimentos específicos da teoria do discurso, Habermas coloca o princípio moral e o princípio democrático. O princípio da moral para Habermas simboliza as normas de ação, correspondendo à ações afirmativas que são justificadas levando em conta o interesse de todos, de forma igualitária. Desta forma, o princípio da moralidade estaria atrelado ao princípio da universalização. 
Para Habermas ${ }^{7}$, portanto, o princípio moral, o princípio da universalidade, o princípio da legalidade e o princípio da democracia estão atrelados, havendo uma junção entre Direito, Moralidade e Democracia.

Nesse passo, o princípio da democracia abre um campo de discussões na quais abrangem vários tipos de discursos seja morais, éticos, pragmáticos, incluindo as negociações, de maneira a modelar as normas jurídicas. Portanto, o princípio da democracia fixa os parâmetros e legitima a produção do próprio direito.

[...] Por "direito" eu entendo o moderno direito normatizado, que se apresenta com a pretensão à fundamentação sistemática, à interpretação obrigatória e à imposição. $\mathrm{O}$ direito não representa apenas uma forma do saber cultural, como a moral, pois forma, simultaneamente, um componente importante do sistema de instituições sociais. O direito é um sistema de saber e, ao mesmo tempo, um sistema de ação. (HABERMAS, 2003, p. 110-111).

O Direito, atuando como regulador do princípio democrático interliga as decisões tomadas nos processos de discussão de forma a torná-las efetivas no plano prático, o que não ocorre com a moralidade. Portanto, é no âmbito do Direito que tais discursos encontram espaços públicos institucionalizados para o seu desenvolvimento e sua prática, mantendo uma ligação com a moralidade, de forma a alcançar efetivamente a aplicação do princípio democrático através da busca da legitimidade do Discurso.

A jurisdição, portanto, não pode desenvolver o direito por uma interpretação construtiva desconectada do poder comunicativo. O poder comunicativo, que é a única fonte de legitimação do Estado de Direito, só se exerce argumentativamente através de um

\footnotetext{
7 "Uma norma jurídica não pode limitar-se apenas a garantir que toda pessoa seja reconhecida em seus direitos por todas as demais pessoas; o reconhecimento recíproco dos direitos de cada um por todos os outros deve apoiar-se, além disso, em leis legítimas que garantam a cada um liberdades iguais, de modo que 'a liberdade do arbítrio de cada um possa manter-se junto com a liberdade de todos'. As leis morais preenchem esta condição per se; no caso das regras do direito positivo, no entanto, essa condição precisa ser preenchida pelo legislador político. No sistema jurídico, o processo da legislação constitui, pois, o lugar propriamente dito da integração social. Por isso, temos que supor que os participantes do processo de legislação saem do papel de sujeitos privados do direito e assumem, através do seu papel de cidadãos, a perspectiva de membros de uma comunidade jurídica livremente associada, na qual um acordo sobre os princípios normativos da regulamentação da convivência já está assegurado através da tradição ou pode ser conseguido através de um entendimento segundo regras reconhecidas normativamente. Essa união característica entre coerção fática e validade da legitimidade, que tentamos esclarecer através do direito subjetivo à assunção estratégica de interesses próprios, exige um processo de legislação no qual os cidadãos devem poder participar na condição de sujeitos do direito que agem orientados não apenas pelo sucesso. Na medida em que os direitos de comunicação e de participação política são constitutivos para um processo de legislação eficiente do ponto de vista da legitimação, esses direitos subjetivos não podem ser tidos como os de sujeitos jurídicos privados e isolados: eles têm que ser apreendidos no enfoque de participantes orientados pelo entendimento. É por isso que o conceito do direito moderno - que intensifica e, ao mesmo tempo, operacionaliza a tensão entre a facticidade e validade na área do comportamento - absorve o pensamento democrático, desenvolvido por Kant e Rousseau, segundo o qual a pretensão de legitimidade de uma ordem jurídica construída com direitos subjetivos só pode ser resgatada através da força socialmente integradora da "vontade unida e consciente de todos' os cidadãos livres e iguais." (HABERMAS, 2003, p. 52-53).
} 
procedimento institucionalizado com base no princípio do discurso, vale dizer, só se exerce nas condições ideais de uma discussão pública com a participação de todos os implicados. Por isso, nem um órgão colegiado e muito menos um juízo monocrático pode pretender interpretar construtivamente o direito. O Poder Jurisdicional não é hierarquicamente superior ao poder comunicativo. A jurisdição não pode, portanto, submeter a si o poder comunicativo, porque ele é a fonte de toda legitimação do direito e do Estado de Direito. Até porque a legislação implícita, criada pela jurisdição, coloca em risco a racionalidade o exercício do direito e sobrecarrega a base de legitimação do Poder Judiciário. Por mais conhecimentos técnicos e experiência que os especialistas do direito possuam, as decisões jurídicas provocam conseqüência para sociedade, que não podem ser legitimadas por discursos técnicos de especialistas na interpretação direito: a interpretação da Constituição e dos objetivos das políticas públicas não é monopólio da jurisdição. Como se vê, na teoria o discurso de Habermas, o poder jurisdicional sofre restrições. Porque no paradigma procedimentalista do direito, a jurisdição está subordinada ao poder comunicativo da autonomia política dos cidadãos. E é exatamente as condições para o exercício dessa autonomia política, como gênese do processo democrático que a jurisdição tem que proteger. (SIMIONI, 2007, p. 212-213).

A crítica feita à Habermas corresponderia à sua aplicabilidade prática, pois, afirma-se que a teoria habermasiana poderia ocasionar arbitrariedades ou omissões do Poder Judiciário, acarretando o desequilíbrio, e a impossibilitar a aplicação do ideal de que todos os atingidos e possíveis atingidos pelas decisões judiciais ou legais devam participar delas de forma ativa devido à impossibilidade de haver um consenso generalizado entre todos os participantes.

Tais argumentos não convencem tendo em vista que não apenas pelo consenso, mas pelo dissenso pode a opinião do povo, por intermédio de sua participação na política, produzir o direito.

Portanto, a tarefa de reconstrução do Direito no entendimento de Habermas ${ }^{8}$ é assegurar e possibilitar por intermédio do discurso, o exercício simultâneo da autonomia pública e privada dos cidadãos não apenas nos discursos de justificação, ou seja, de formação das leis, mas sim também nos discursos de aplicação jurisdicional do Direito.

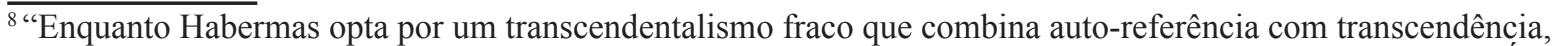
Luhmann opta por uma perspectiva radical, antitranscendental, baseada tão - somente na auto - referência. É esse detalhe sutil que cria a diferença entre a perspectiva reconstrutiva de Habermas e a perspectiva descritiva de Luhmann. E é esse detalhe também que cria, em Habermas, a esperança de vencer a finitude de um futuro (transcendental) que pode ser melhorado comunicativamente, onde Luhmann vê apenas a produção da incerteza e do risco vinculados sempre a expectativas criadas pela trajetória evolutiva dos sistemas. Não se pode esquecer também que desse detalhe surge a diferença entre a descrição da sociedade, em Habermas, como uma relação linear de oposição - Habermas fala em tensão - entre sistema e "mundo vivido", que Luhmann prefere ver como uma relação recursiva, não linear - e por isso inclusiva - entre sistema e ambiente." (SIMIONI, 2007, p. 286.).
} 


\section{CONSIDERAÇÕES FINAIS}

As escolhas políticas do administrador em relação à destinação do orçamento público deveriam ser produzidas com a oitiva do administrado, ou seja, com a participação popular, de modo a haver maior transparência e eficiência dos atos do Poder Público na destinação de verbas para a prestação dos direitos sociais. ${ }^{9}$

Por fim, é imprescindível, com o amparo do legislador infraconstitucional e com o controle judicial sobre os atos administrativos, uma Administração Pública mais ativa no sentido de melhorar a eficácia e a efetividade dos direitos fundamentais sociais prestacionais, que possuem caráter emergencial, e fazer com que a população mais carente receba esse auxílio com qualidade, além do "mínimo existencial", sendo para isso necessária a realização de políticas públicas ${ }^{10}$, de programas orçamentários e sociais mais eficazes, empregando com mais sabedoria os recursos públicos de maneira a alcançar a população hipossuficiente financeiramente, que necessita do efetivo auxílio do Poder Público, respeitando e aplicando efetivamente os princípios da dignidade da pessoa humana e da igualdade.

Ademais, pelo presente estudo, conclui-se que o tipo ideal de democracia é aquela em que há um aprofundamento da identidade popular, possibilitando que as funções públicas sejam exercidas com maior participação dos cidadãos, criando-se novos espaços públicos e novos agentes.

Seguindo o entendimento de Canotilho (2001, p. 288), ao pressupor a participação igual dos cidadãos, o princípio democrático entrelaça-se com os direitos subjetivos de participação e de associação, que se tornam, assim, fundamentos funcionais da democracia.

Portanto, além do já explanado, conclui-se que a missão atribuída ao Poder Judiciário de "guardião da Constituição" exige a possibilidade de repensar o exercício da atividade jurisdicional, tendo em vista que controlar as políticas públicas significa não só a aplicação da lei, mas também a preocupação do agente público com o bem da comunidade, de maneira a atentar

\footnotetext{
9 “O Direito Administrativo tradicional vem sofrendo profundas alterações decorrentes da institucionalização de políticas públicas e da inserção dos debates sobre o tema no campo jurídico-administrativo. Deixa-se, assim, de centrar a discussão na órbita exclusiva dos atos administrativos, ampliando o leque de problematizações para uma instância antecedente a qualquer decisão dos agentes públicos. Não há como focar adequadamente o tema das políticas públicas num cenário de complexidade, como o atual, sem centrar o debate sobre os regimes políticos que constroem o modo-de-ser cultural dos cidadãos e da própria Administração Pública. Os estudos sobre a questão dos programas de governo partem de pressupostos analíticos e abstratos, olvidando que construir políticas públicas está diretamente relacionado com os diversos contextos públicos". (OHLWEILER, 2008, p. 343). ${ }^{10}$ Segundo Ana Paula de Barcellos $(2008$, p. 117) no texto Constitucionalização das políticas públicas em matéria de direitos fundamentais: o controle político-social e o controle jurídico no espaço democrático: "As políticas públicas, igualmente, envolvem gastos. E como não há recursos ilimitados, será preciso priorizar e escolher em que o dinheiro público disponível será investido. Além da definição genérica de em que gastar, é preciso ainda decidir como gastar, tendo em conta os objetivos específicos que se deseje alcançar".
} 
realmente para as mazelas sociais, inibindo os administradores públicos de terem ampla liberdade com a coisa pública.

Nesse passo, destaca-se o ensinamento de Habermas que, por intermédio do discurso, da ação comunicativa, buscam-se alternativas filosóficas para que possam fundar a integração social e a racionalidade nos processos sociais de formação democrática da vontade do povo. $\mathrm{O}$ discurso promove a inclusão de toda e qualquer minoria. ${ }^{11}$

A herança deixada por Habermas é o fato de que em um Estado Democrático de Direito, todos os atingidos e possíveis atingidos pelas decisões judiciais devem participar delas de forma ativa.

Desta forma, ao intensificar a participação direta e ativa do povo haverá a democratização da democracia, estimulando, portanto, a mobilização social na destinação dos recursos públicos.

As escolhas políticas do administrador em relação à destinação do orçamento público deveriam ser produzidas com a oitiva do administrado, ou seja, com a participação popular, de modo a haver maior transparência e eficiência dos atos do Poder Público na destinação de verbas para a prestação dos direitos sociais.

Por fim, seguindo o modelo de Porto Alegre, constata-se a necessidade de uma Administração Pública mais ativa no sentido de empregar com sabedoria os recursos públicos e, através da co - participação popular, elaborar programas orçamentários e sociais eficazes, de maneira que a prestação dos serviços públicos possa efetivamente alcançar a população mais carente.

Ademais, pelo presente estudo, conclui-se que o tipo ideal de democracia é aquela em que há um aprofundamento da identidade popular, possibilitando que as funções públicas sejam exercidas com maior participação dos cidadãos, criando-se novos espaços públicos e novos agentes.

Portanto, conforme explanado, conclui-se que é necessário que o Poder Público reflita sobre a necessidade do resgate da democracia direta participativa, tornando o povo colaborador

\footnotetext{
11 "O ativismo judicial se insere no Brasil dentro de um mundo da vida em que os juízes, de uma forma geral, não se sentem servidores públicos, e sim, entes transcendentalmente superiores. Acostumados à cortesia e às posturas formalistas, não é incomum a figura do magistrado distante das pessoas e do "mundo" que espera apenas a bajulação e desconsidera as necessidades das partes. Dizer a eles que podem tudo, ou melhor, que devem fazer tudo, tal como fazem os teóricos do constitucionalismo da efetividade, é música para seus ouvidos! Não desconhecemos que as intenções dessa corrente teórica são boas e favoráveis à inclusão social. Mas é preciso lembrar o ditado: o inferno está cheio de boas intenções. $\mathrm{O}$ ativismo judicial desmedido por noções vazias como "razoabilidade" e "proporcionalidade" pode ser um bálsamo, como pretendem seus adeptos, mas também pode ser um veneno para nossa democracia ainda incipiente. Sem pretensão de estabelecer "verdades”, no mínimo, acreditamos firmemente que a denúncia de Habermas serve de base para reflexão do modo de operação do direito e do constitucionalismo nacionais." (CRUZ, 2008, p. 251).
} 
e co - responsável pela elaboração dos orçamentos públicos e destinação dos recursos, de maneira a atentar realmente para as mazelas sociais, inibindo os administradores públicos de terem ampla liberdade com a coisa pública e se esquecerem de beneficiar a maioria da população.

\section{REFERÊNCIAS}

BARCELLOS, Ana Paula de. Constitucionalização das políticas públicas em matéria de direitos fundamentais: o controle político-social e o controle jurídico no espaço democrático. In:

SARLET, Ingo Wolfgang; TIMM, Luciano Benetti (Org.). Direitos fundamentais, orçamento e "reserva do possível". Porto Alegre: Livraria do Advogado, 2008. p. 111-147.

CANOTILHO, José Joaquim Gomes. Direito Constitucional e teoria da constituição. Coimbra: Almedina, 2001.

CRUZ, Álvaro Ricardo de Souza. Habermas e o direito brasileiro. 2. ed. Rio de Janeiro: Lúmen Júris Editora, 2008.

HABERMAS, Jürgen. Direito e Democracia entre a facticidade e a validade. 2. ed. Rio de Janeiro: Tempo Brasileiro, 2003. v.1.

. Direito e democracia entre a facticidade e a validade. 2. ed. Rio de Janeiro: Tempo Brasileiro, 2003. v.1.

MELO, Danielle; AMARAL, Gustavo. Há direitos acima dos orçamentos? In: SARLET, Ingo Wolfgang; TIMM, Luciano Benetti (Org.). Direitos fundamentais, orçamento e "reserva do possível”. Porto Alegre: Livraria do Advogado, 2008. p.87-109.

MÜLLER, Friedrich. Quem é o povo? 4. ed. São Paulo: RT, 2008.

OHLWEILER, Leonel Pires. Políticas Públicas e controle jurisdicional: uma análise hermenêutica à luz do Estado democrático de direito. In: SARLET, Ingo Wolfgang; TIMM, Luciano Benetti (Org). Direitos fundamentais, orçamento e "reserva do possível". Porto Alegre: Livraria do Advogado, 2008. p. 323-345.

OLIVEIRA, Marcelo Andrade Cattoni de. Direito, política e filosofia: contribuições para uma teoria discursiva da constituição democrática no marco do patriotismo constitucional. Rio de Janeiro: Lúmen Júris, 2007.

PEREIRA, Rodolfo Viana. Direito constitucional democrático. Rio de Janeiro: Lúmen Júris, 2008.

REPOLÊS, Maria F. S. Habermas e a desobediência civil: mandamentos. Belo Horizonte, 2003. 
SARLET, Ingo Wolfgang. A eficácia dos direitos fundamentais. 9. ed. Porto Alegre: Livraria do Advogado, 2008.

SARLET, Ingo Wolfgang. Algumas considerações em torno do conteúdo, eficácia e efetividade do direito à saúde na constituição de 1988. Revista Diálogo Jurídico, Salvador, n. 10, jan. 2002. Disponível em: <http://www.direitopublico.com.br>. Acesso em: 6 maio 2008.

SARLET, Ingo Wolfgang; FIGUEIREDO, Mariana Filchtiner. Reserva do possível, mínimo existencial e direito à saúde: algumas aproximações. In: SARLET, Ingo Wolfgang; TIMM, Luciano Benetti (Org). Direitos fundamentais, orçamento e "reserva do possível". Porto Alegre: Livraria do Advogado, 2008. p. 11-53.

SIMIONI, Rafael Lazzarotto. Direito e racionalidade comunicativa: a teoria discursiva do direito no pensamento de Jürgen Habermas. Curitiba: Juruá, 2007.

SIMIONI, Rafael Lazzarotto. Poder e autopoiese da política em Niklas Luhmann. Revista da Faculdade de Direito do Sul de Minas, Pouso Alegre, v. 27, p.119-129, jul/dez. 2008.

SOARES, Mário Lúcio Quintão. Teoria do estado. Belo Horizonte: Del Rey, 2001.

TIMM, Luciano Benetti. Qual a maneira mais eficiente de prover direitos fundamentais: uma perspectiva de direito e economia. In: SARLET, Ingo Wolfgang; TIMM, Luciano Benetti (Org). Direitos fundamentais, orçamento e "reserva do possível". Porto Alegre: Livraria do Advogado, 2008. p. 55-68.

TORRES, Ricardo Lobo. O mínimo existencial, os direitos sociais e os desafios de natureza orçamentária. In: SARLET, Ingo Wolfgang; TIMM, Luciano Benetti (Org). Direitos fundamentais, orçamento e "reserva do possível". Porto Alegre: Livraria do Advogado, 2008. p. 69-86. 